\title{
Knowledge of Systemic Diseases Presenting the Oral Signs and Symptoms: A Short Review
}

\author{
Himanshu Singh ${ }^{1}$ Vedant Patel ${ }^{2}$ Rahul A. Razdan² \\ Divya Jain ${ }^{5}$
}

Resham Maheshwari $^{3}$ Sourabh Sharma ${ }^{4}$

\begin{abstract}
Address for correspondence Himanshu Singh, MDS, Department of Oral Pathology and Oral Microbiology, Index Institute of Dental Sciences, Indore 452016, Madhya Pradesh, India (e-mail: himanshustar3g@gmail.com).
\end{abstract}

\begin{abstract}
Keywords

- oral manifestations

- systemic diseases

- disorders

The accurate examination of oral cavity may acknowledge findings that demonstrate the presence of underlying systemic, which helps in earlier diagnosis as well as treatment. The oral tissues are accountable to damage as a disease consequence that primarily affects other body systems. Various systemic diseases show oral manifestation. Some of these oral conditions include oral ulcers, caries, dry mouth, gingival bleeding, and gingival hypertrophy. This review article is prepared to make general physicians as well as dentist aware about systemic disorders or conditions that show dental or oral manifestation.
\end{abstract}

Dent J Adv Stud 2019;7:56-60

\section{Introduction}

Inadequate oral health is an utmost problem worldwide. There are many investigations done to check the relationship between various systemic diseases and oral health. Various epidemiology-based studies have related the bad oral conditions to different conditions such as cardiovascular diseases, respiratory diseases, adverse pregnancy outcomes, stroke, malignant diseases, obesity, and rheumatoid arthritis. ${ }^{1-5}$

Oral inspection or investigation shows clinical features of various diseases such as hematologic conditions, endocrinopathies, immunologic diseases, nutritional disorder, and systemic infections. ${ }^{6}$ Mouth may be considered as a reflector of diseases or health. Various systemic diseases show their oral manifestation. ${ }^{7}$

\section{Various Systemic Diseases with Their Oral Manifestation}

\section{Pulmonary Disorder and Oral Manifestation \\ Chronic Obstructive Pulmonary Diseases}

Smoking is considered as a significant risk factor for chronic obstructive pulmonary disease (COPD) as well as periodontal abnormalities. As per the study conducted by Katancik et al in 2005, a remarkable relationship between periodontal disorders and airway obstruction was noticed. ${ }^{8}$ Another study was conducted by Prasanna in 2011 to check the relationship between periodontal diseases and COPD. He proposed that periodontitis is important risk factors for COPD. ${ }^{9}$

In the year 2014, Öztekin et al in their study noted that there is association between the periodontal diseases and COPD. ${ }^{10}$ received

July 28, 2019

accepted

July 29, 2019

published online

October 18, 2019
Dol https://doi.org/

10.1055/s-0039-1698361

ISSN 2321-1482.
(C)2019 Bhojia Dental College and

Hospital affiliated to Himachal

Pradesh University
License terms

() (1) $\Theta \circledast$ 


\section{Asthma}

According to Thomas et al, most common oral conditions that are related to asthma are periodontal diseases, dental cavities, oral candidiasis, and erosions ${ }^{11}$ principally asthmatic patients possess habit of breathing from mouth. As a result, gingival inflammation occurs because of alveolar mucosa dryness. ${ }^{12}$

\section{Tuberculosis}

Pulmonary tuberculosis shows oral lesions in primary as well as secondary stages. According to Mignogna et al, 0.05 to $5 \%$ of tuberculosis patients show oral lesions. ${ }^{13}$ Oral manifestations of tuberculosis can be seen in the form of ulcers, fissures, nodules present on the lips, palate, or tongue, along with cervical lymphadenopathy. ${ }^{13,14}$

\section{Sarcoidosis}

Sarcoidosis is an acquired systemic disease. Being a granulomatous disease, it shows the occupancy of granulomas in lungs. Sarcoidosis shows some oral manifestations in the forms of local swellings, palatal ulceration, inflamed gingiva, and labial as well as buccal mucosa ulceratios. ${ }^{15}$

\section{Wegener Granulomatosis}

Wegener granulomatosis is considered as systemic diseases categorized as necrotizing granulomatous inflammation of small-to-medium vessels. The oral manifestation is expressed as oral mucosal ulceration or palatal ulceration and mobile tooth. "Strawberry gingivitis" can be seen. ${ }^{16,17}$

\section{Pneumonia}

Limeback ${ }^{18}$ observed in his study that a patient who is suffering from aspiration pneumonia should have poor oral hygiene. In another study by Loesche and Lopatin, ${ }^{19}$ it was noted that patients who are suffering from aspirational pneumonia have more chances of having periodontitis.

\section{Gastrointestinal Disorder and Oral Manifestation Crohn's Diseases}

Oral manifestations noted in Crohn's diseases are commonly seen in young patients with 20 to $50 \%$ prevalence range. ${ }^{20}$ The oral manifestations include papules, ulcers, and edema with most common locations such as gingiva, lips, and vestibular sulci. ${ }^{21,22}$

Dupuy et al observed in their study that $0.5 \%$ of the patients suffering from Crohn's diseases show oral manifestations. Oral lesions are nodular or linear or have diffuse mucosal thickenings. They are generally firm and painless while examining. But, if they are ulcers, they possess severe pain on pressing. These ulcers are constant and deep. ${ }^{23}$

\section{Ulcerative Colitis}

Pellicer et $\mathrm{al}^{24}$ stated that ulcerative colitis shows oral manifestations in the form of superficial hemorrhagic ulcers, aphthous ulcers, or angular cheilitis. Elahi et $\mathrm{al}^{25}$ observed in their study that patients having ulcerative colitis show higher frequency of tongue coating, oral ulceration, acidic taste, halitosis, and dry mouth.
Celiac diseases show various oral manifestations. Patients having celiac diseases exhibit increased possibility of developmental enamel defects mainly enamel hypoplasia. ${ }^{26}$ Because of the celiac disease, there is decreased rate of flow of saliva that in turn results in dry mouth. ${ }^{27}$

Avşar and Kalayci ${ }^{28}$ observed in their study that the children with celiac disease have increased risk of enamel defects and these enamel defects are responsible for occurrence of caries.

\section{Gastroesophageal Reflux Diseases}

Di Fede et $\mathrm{al}^{29}$ noted in their study the significant relationship between gastroesophageal reflux disease (GERD) and erythema of palatal mucosa as well as uvula. Wang et $\mathrm{al}^{30}$ in their study observed a significant relationship between GERD and dental erosions.

Schroeder et $\mathrm{al}^{31}$ in their study also observed that dental erosion is usually seen in GERD patients. Another oral manifestation seen in GERD is halitosis. Moshkowitz et al conducted a study to analyze the association between GERD and halitosis. They observed that halitosis is a routine manifestation of GERD. ${ }^{32}$

\section{Hematologic Disorder and Oral Manifestation Anemia}

Most frequent hematologic disorder is anemia. Iron deficiency anemia shows oral manifestation in the form of mucosal pallor, atrophic glossitis, and angular cheilits. ${ }^{33}$ Sickle cell anemia shows mandibular salmonella osteomyelitis, pulpal necrosis, and mandibular nerve paresthesia as oral manifestations. It also shows enamel hypomineralization, orofacial pain as well as diastema. ${ }^{34-36}$

\section{Leukemia}

Leukemia shows various forms of oral manifestations that include petechiae, gingival hypertrophy, ecchymosis, hemorrhage, and mucosal ulcers. ${ }^{37}$ Numb chin syndrome may be seen occasionally. ${ }^{38}$

In case of acute myeloid leukemia, most common oral features seen are oral ulceration, gingival bleeding, and gingival hyperplasia. Also, spontaneous bleeding can be seen in palate, gingiva, lips, or tongue. Oral ulcerations can be noted very commonly. ${ }^{39-41}$ In patients who are suffering from acute lymphoblastic leukemia, oral features include gingival bleeding and ecchymoses along with lymphadenopathy that is a persistent sign. ${ }^{42}$

Additionally, in case of chronic lymphocytic leukemia, oral features seen include localized swelling with pain and ulcers. Gingival bleeding as well as purpura can be noted. ${ }^{41,43}$ Some features such as gingival leukemic infiltration and palatal enlargement are linked with chronic lymphocytic leukemia. ${ }^{44,45}$

\section{Liver Diseases and Oral Manifestation}

In liver malfunctioning, the oral cavity displays some manifestations in the form of gingivitis, gingival bleeding, mucosal membrane jaundice, petechiae, fetor hepaticus, xerostomia, and atrophic tongue. Chronic periodontal disease is the most common disease in these patients. ${ }^{46-48}$ 
Some manifestations such as gingivitis, angular cheilitis, and glossitis can be seen in patients suffering from alcoholic hepatitis. ${ }^{46,49} \mathrm{~A}$ study was conducted by Bagán et al ${ }^{50}$ to check the dental status in patients having cirrhosis of liver. They noted the remarkable number of missing teeth and carious teeth in patients with cirrhosis of liver and concluded that substandard dental status was seen.

\section{Renal Diseases and Oral Manifestation}

Renal diseases may show various oral manifestations. These include mucositis, stomatitis, and glossitis that in turn lead to inflammation along with pain of oral mucosa and tongue. Also, some other manifestations, such as dysgeusia, Candida infection, and altered taste sensations, are established because of renal diseases. ${ }^{51}$

In a study done by Martins et al, ${ }^{52}$ it was observed that those chronic renal failure patients (children and adolescents) undergoing hemodialysis may show oral manifestations that include delayed tooth eruption, dry mouth, dental stains, and calculus. Koch et $\mathrm{a}^{53}$ in their study noted that cases of chronic renal failure may influence the development of enamel in primary teeth that result in enamel hypoplasia.

Galili et $\mathrm{a}^{54}$ in 1991 conducted a study to compare the dental pulp size in chronic renal diseases with healthy controls. They observed the significant relationship between renal diseases and narrowing of pulp in premolar as well as molar teeth. Jaffe et $\mathrm{al}^{55}$ in their study concluded that children suffering from chronic renal failure shows delay in dental maturation.

\section{Endocrine Disorders and Oral Manifestation Diabetes Mellitus}

Diabetes mellitus shows number of oral manifestations. The majority of patients suffering from diabetes shows xerostomia because of restricted salivary flow and rise in salivary glucose level. Other factors that contribute to oral manifestations include increased vulnerability to infections, collection of plaque and food debris, and poor healing. ${ }^{56}$

Falk et $\mathrm{al}^{57}$ in their study have observed the high frequency of dental caries in poorly controlled diabetic patients. Also, these patients show occurrence of loss of periodontal attachment. $^{58}$

\section{Hyperparathyroidism}

Most common oral manifestations seen in oral cavity include mobility of teeth, loss of bone density, and variations in tooth eruption calcifications of soft tissue. Also, loss of lamina dura with changes in jaw trabecular pattern can be seen. ${ }^{59-62}$

\section{Hypoparathyroidism}

Most common manifestations seen in hypoparathyroidism are enamel hypoplasia and delayed eruption. ${ }^{63}$ Some teeth show root malformation along with interruption in the dental development and growth. ${ }^{64}$ Facial twitching with lip or tongue paresthesia can also occur. Radiographic features, such as wide root canal, large pulp chambers, and thickened lamina dura, are some other oral manifestations. .5.66 $^{6}$

\section{Hyperthyroidism}

Variety of oral manifestations are seen in cases of hyperthyroidism. Periodontal diseases, osteoporosis of maxillary, or mandibular portion of jaw increased vulnerability to dental caries and expedited dental growth. ${ }^{67}$

\section{Hypothyroidism}

Hypothyroidism shows various oral manifestations that appear in the form of dysgeusia, substandard periodontal conditions, enlarged tongue, and delayed healing of wound. ${ }^{68}$

\section{Conclusion}

The consequence of systemic diseases on oral cavity is well noted and it includes various soft tissue and hard tissue abnormality as well as pathology. Oral manifestation is the first sign of systemic diseases. General physicians and dentist need to be mindful of understanding the oral complaints.

\section{Conflict of Interest}

None declared.

\section{References}

1 Lux J. Review of the oral disease-systemic disease link. Part 1: heart disease, diabetes. Can J Dental Hyg 2006;40(6):288-342

2 Lux J. Review of the oral disease-systemic disease link. Part II: preterm low birth weight babies, respiratory disease. Can J Dental Hyg 2007;41(1):8-21

3 Kinane D, Bouchard P; Group E of European Workshop on Periodontology. Periodontal diseases and health: consensus report on the sixth European workshop on periodontology. J Clin Periodontol 2008;35(8, Suppl):333-337

4 Seymour GJ, Ford PJ, Cullinan MP, Leishman S, Yamazaki K. Relationship between periodontal infections and systemic disease. Clin Microbiol Infect 2007;13(Suppl 4):3-10

5 Seymour RA. Is gum disease killing your patient? Br Dent J 2009;206(10):551-552

6 Xiong X, Buekens P, Fraser WD, Beck J, Offenbacher S. Periodontal disease and adverse pregnancy outcomes: a systematic review. BJOG 2006;113(2):135-143

7 Long RG, Hlousek L, Doyle JL. Oral manifestations of systemic diseases. Mt Sinai J Med 1998;65(5-6):309-315

8 Katancik JA, Kritchevsky S, Weyant RJ, et al. Periodontitis and airway obstruction. J Periodontol 2005;76(11):2161-2167

9 Prasanna SJ. Causal relationship between periodontitis and chronic obstructive pulmonary disease. J Indian Soc Periodontol 2011;15(4):359-365

10 Öztekin G, Baser U, Kucukcoskun M, et al. The association between periodontal disease and chronic obstructive pulmonary disease: a case control study. COPD 2014;11(4):424-430

11 Thomas MS, Parolia A, Kundabala M, Vikram M. Asthma and oral health: a review. Aust Dent J 2010;55(2):128-133

12 Stensson M, Wendt LK, Koch G, Oldaeus G, Birkhed D. Oral health in preschool children with asthma. Int J Paediatr Dent 2008;18(4):243-250

13 Mignogna MD, Muzio LL, Favia G, et al. Oral tuberculosis: a clinical evaluation of 42 cases. Oral Dis 2000;6(1):25-30

14 Sezer B, Zeytinoglu M, Tuncay U, Unal T. Oral mucosal ulceration: a manifestation of previously undiagnosed pulmonary tuberculosis. J Am Dent Assoc 2004;135(3):336-340

15 Suresh L, Radfar L. Oral sarcoidosis: a review of literature. Oral Dis 2005;11(3):138-145 
16 Ruokonen $\mathrm{H}$, Helve T, Arola J, Hietanen J, Lindqvist C, Hagstrom J. "Strawberry like" gingivitis being the first sign of Wegener's granulomatosis. Eur J Intern Med 2009;20(6):651-653

17 Aravena V, Beltrán V, Cantín M, Fuentes R. Gingival hyperplasia being the first sign of Wegener's granulomatosis. Int J Clin Exp Med 2014;7(8):2373-2376

18 Limeback $\mathrm{H}$. The relationship between oral health and systemic infections among elderly residents of chronic care facilities: a review. Gerodontology 1988;7(4):131-137

19 Loesche WJ, Lopatin DE, Interactions between periodontal disease, medical diseases and immunity in the older individual. Periodontology 2000;16:80-105

20 Lisciandrano D, Ranzi T, Carrassi A, et al. Prevalence of oral lesions in inflammatory bowel disease. Am J Gastroenterol 1996;91(1):7-10

21 Lankarani KB, Sivandzadeh GR, Hassanpour S. Oral manifestation in inflammatory bowel disease: a review. World J Gastroenterol 2013;19(46):8571-8579

22 Plauth M, Jenss H, Meyle J. Oral manifestations of Crohn's disease. An analysis of 79 cases. J Clin Gastroenterol 1991;13(1):29-37

23 Dupuy A, Cosnes J, Revuz J, Delchier JC, Gendre JP, Cosnes A. Oral Crohn disease: clinical characteristics and long-term follow-up of 9 cases. Arch Dermatol 1999;135(4):439-442

24 Pellicer Z, Santiago JM, Rodriguez A, Alonso V, Antón R, Bosca MM. Management of cutaneous disorders related to inflammatory bowel disease. Ann Gastroenterol 2012;25(1):21-26

25 Elahi M, Telkabadi M, Samadi V, Vakili H. Association of oral manifestations with ulcerative colitis. Gastroenterol Hepatol Bed Bench 2012;5(3):155-160

26 Mantegazza C, Paglia M, Angiero F, Crippa R. Oral manifestations of gastrointestinal diseases in children. Part 4: Coeliac disease. Eur J Paediatr Dent 2016;17(4):332-334

27 Costacurta M, Maturo P, Bartolino M, Docimo R. Oral manifestations of coeliac disease: a clinical-statistic study. Oral Implantol (Rome) 2010;3(1):12-19

28 Avşar A, Kalayci AG. The presence and distribution of dental enamel defects and caries in children with celiac disease. Turk J Pediatr 2008;50(1):45-50

29 Di Fede O, Di Liberto C, Occhipinti G, et al. Oral manifestations in patients with gastro-oesophageal reflux disease: a single-center case-control study. J Oral Pathol Med 2008;37(6):336-340

30 Wang GR, Zhang H, Wang ZG, Jiang GS, Guo CH. Relationship between dental erosion and respiratory symptoms in patients with gastro-oesophageal reflux disease. J Dent 2010;38(11):892-898

31 Schroeder PL, Filler SJ, Ramirez B, Lazarchik DA, Vaezi MF, Richter JE. Dental erosion and acid reflux disease. Ann Intern Med 1995;122(11):809-815

32 Moshkowitz M, Horowitz N, Leshno M, Halpern Z. Halitosis and gastroesophageal reflux disease: a possible association. Oral Dis 2007;13(6):581-585

33 McFarlane DB, Pinkerton PH, Dagg JH, Goldberg A. Incidence of iron deficiency, with and without anaemia, in women in general practice. Br J Haematol 1967;13(5):790-796

34 Kelleher M, Bishop K, Briggs P. Oral complications associated with sickle cell anemia: a review and case report. Oral Surg Oral Med Oral Pathol Oral Radiol Endod 1996;82(2):225-228

35 Andrews $\mathrm{CH}$, England MC, Jr. Kemp WB. Sickle cell anemia: an etiological factor in pulpal necrosis. J Endod 1983;9(6):249-252

36 Taylor LB, Nowak AJ, Giller RH, Casamassimo PS. Sickle cell anemia: a review of the dental concerns and a retrospective study of dental and bony changes. Spec Care Dentist 1995;15(1):38-42

37 Lynch MA, Ship II. Initial oral manifestations of leukemia. J Am Dent Assoc 1967;75(4):932-940
38 Hiraki A, Nakamura S, Abe K, et al. Numb chin syndrome as an initial symptom of acute lymphocytic leukemia: report of three cases. Oral Surg Oral Med Oral Pathol Oral Radiol Endod 1997;83(5):555-561

39 Stafford R, Sonis S, Lockhart P, Sonis A. Oral pathoses as diagnostic indicators in leukemia. Oral Surg Oral Med Oral Pathol 1980;50(2):134-139

40 Cooper CL, Loewen R, Shore T. Gingival hyperplasia complicating acute myelomonocytic leukemia. J Can Dent Assoc 2000;66(2):78-79

41 Hou GL, Huang JS, Tsai CC. Analysis of oral manifestations of leukemia: a retrospective study. Oral Dis 1997;3(1):31-38

42 Declerck D, Vinckier F. Oral complications of leukemia. Quintessence Int 1988;19(8):575-583

43 Kemp S, Gallagher G, Kabani S, Noonan V, O'Hara C. Oral non-Hodgkin's lymphoma: review of the literature and World Health Organization classification with reference to 40 cases. Oral Surg Oral Med Oral Pathol Oral Radiol Endod 2008;105(2):194-201

44 Presant CA, Safdar SH, Cherrick H. Gingival leukemic infiltration in chronic lymphocytic leukemia. Oral Surg Oral Med Oral Pathol 1973;36(5):672-674

45 Henefer EP, Nelson JF, Beaupre EM. Palatal enlargement in chronic lymphocytic leukemia: report of case. J Oral Surg 1970;28(5):371-375

46 Golla K, Epstein JB, Cabay RJ. Liver disease: current perspectives on medical and dental management. Oral Surg Oral Med Oral Pathol Oral Radiol Endod 2004;98(5):516-521

47 Hazin R, Abu-Rajab Tamimi TI, Abuzetun JY, Zein NN. Recognizing and treating cutaneous signs of liver disease. Cleve Clin J Med 2009;76(10):599-606

48 Grau-García-Moreno DM. [Dental management of patients with liver disease]. Med Oral 2003;8(3):231

49 Friedlander AH, Marder SR, Pisegna JR, Yagiela JA. Alcohol abuse and dependence: psychopathology, medical management and dental implications. J Am Dent Assoc 2003;134(6):731-740

50 Bagán JV, Alapont L, Sanz C, et al. [Dental and salivary alterations in patients with liver cirrhosis: a study of 100 cases] Med Clin (Barc) 1998;111(4):125-128

51 Thomas $\mathrm{C}$. The roles of inflammation and oral care in the overall wellness of patients living with chronic kidney disease. Dent Econ 2008;98:111-120

52 Martins C, Siqueira WL, Guimarães Primo LS. Oral and salivary flow characteristics of a group of Brazilian children and adolescents with chronic renal failure. Pediatr Nephrol 2008;23(4):619-624

53 Koch MJ, Bührer R, Pioch T, Schärer K. Enamel hypoplasia of primary teeth in chronic renal failure. Pediatr Nephrol 1999;13(1):68-72

54 Galili D, Berger E, Kaufman E. Pulp narrowing in renal end stage and transplanted patients. J Endod 1991;17(9):442-443

55 Jaffe EC, Roberts GJ, Cahntler C, Carter JE. Dental maturity in children with chronic renal failure assessed from dental panoramic tomographs. J Int Assoc Dent Child 1990;20(2):54-58

56 Rees TD. The diabetic dental patient. Dent Clin North Am 1994;38(3):447-463

57 Falk H, Hugoson A, Thorstensson H. Number of teeth, prevalence of caries and periapical lesions in insulin-dependent diabetics. Scand. J Dent Res 1989;97(3):198-206

58 Chi AC, Neville BW, Krayer JW, Gonsalves WC. Oral manifestations of systemic disease. Am Fam Physician 2010;82(11):1381-1388

59 Silverman S Jr. Ware WH, Gillooly C Jr, Dental aspects of hyperparathyroidism. Oral Surg Oral Med Oral Pathol 1968;26(2):184-189

60 Silverman S Jr,. Gordan G, Grant T, Steinbach H, Eisenberg E, Manson R. The dental structures in primary 
60 Knowledge of Systemic Diseases Presenting the Oral Signs and Symptoms Singh et al.

hyperparathyroidism. Studies in forty-two consecutive patients. Oral Surg Oral Med Oral Pathol 1962;15:426-436

61 Bridge AJ. Primary hyperparathyroidism presenting as a dental problem. Br Dent J 1968;124(4):172-176

62 Hayes CW, Conway WF. Hyperparathyroidism. Radiol Clin North Am 1991;29(1):85-96

63 Goepferd SJ, Flaitz CM. Enamel hypoplasia associated with congenital hypoparathyroidism. Pediatr Dent 1981;3(2):196-200

64 Kelly A, Pomarico L, de Souza IP. Cessation of dental development in a child with idiopathic hypoparathyroidism: a 5-year follow-up. Oral Surg Oral Med Oral Pathol Oral Radiol Endod 2009;107(5):673-677
65 Takeuchi H, Hioki H, Ishikura Y, Tomizawa M, Noda T, Fukushima M. [Dental findings in a case of idiopathic hypoparathyroidism]. Shoni Shikagaku Zasshi 1989;27(3):678-691

66 Hansted C, Holst G. Changes in dental tissue in hypoparathyroidism. Acta Odontol Scand 1952;10(2):71-74

67 Pinto A, Glick M. Management of patients with thyroid disease: oral health considerations. J Am Dent Assoc 2002;133(7):849-858

68 Young ER. The thyroid gland and the dental practitioner. J Can Dent Assoc 1989;55(11):903-907 